\title{
Percutaneous vertebral augmentation for painful osteolytic vertebral metastasis: a case report
}

This article was published in the following Dove Press journal:

International Medical Case Reports Journal

19 March 2012

Number of times this article has been viewed

\author{
Giovanni C Anselmetti' \\ Sean M Tutton ${ }^{2}$ \\ Francis R Facchini ${ }^{3}$ \\ Larry E Miller ${ }^{4,5}$ \\ Jon E Block ${ }^{5}$ \\ 'Institute for Cancer Research \\ and Treatment, Turin, Italy; \\ ${ }^{2}$ Medical College of Wisconsin in \\ Milwaukee, Froedtert Memorial \\ Lutheran Hospital, Milwaukee, WI, \\ USA; ${ }^{3}$ nterventional Radiology \\ Interventional Oncology, VIR \\ Chicago, Hinsdale, IL, USA; ${ }^{4}$ Miller \\ Scientific Consulting, Inc, Arden, \\ NC, USA; ${ }^{5}$ The Jon Block Group, San \\ Francisco, CA, USA
}

Introduction: Vertebral metastases are associated with significant pain, disability, and morbidity. Open surgery for fracture stabilization is often inappropriate in this population due to a poor risk-benefit profile, particularly if life expectancy is short. Percutaneous vertebroplasty and kyphoplasty are appealing adjunctive procedures in patients with malignancy for alleviation of intractable pain. However, these patients have higher risk of serious complications, notably cement extravasation. Described in this report is a case of a painful osteolytic vertebral metastasis that was successfully treated by a novel percutaneous vertebral augmentation system.

Case presentation: A 42-year-old Caucasian female presented with a history of metastatic lung cancer unresponsive to radiation and chemotherapy with symptoms inadequately controlled by opiates over the previous 6 months. Magnetic resonance imaging and spiral computed tomography with two-dimensional reconstruction showed an osteolytic vertebral metastasis with complete involvement of the T10 vertebral body, extending to the cortical vertebral wall anteriorly and posteriorly. The patient was treated with percutaneous vertebral augmentation (Kiva ${ }^{\circledR}$ VCF Treatment System, Benvenue Medical, Inc, Santa Clara, CA) utilizing a novel coilshaped polyetheretherketone implant designed to minimize the risk of cement extravasation. After the minimally invasive procedure, bone cement distribution within the vertebral body was ideal, with no observed cement extravasation. No complications were reported, pain completely resolved within 24 hours, and use of intravenous narcotics was progressively diminished within 1 week. Complete pain relief was maintained throughout 4 months of follow-up.

Conclusion: The Kiva System represents a novel and effective minimally invasive treatment option for patients suffering from severe pain due to osteolytic vertebral metastasis.

Keywords: Kiva, minimally invasive, pain

\section{Introduction}

Vertebral metastases are associated with significant pain, disability, and morbidity. If left untreated, progression of these lesions results in painful microfractures with potential for vertebral level collapse and spinal cord compromise. Open surgery for fracture stabilization is often inappropriate in this patient population due to a poor risk-benefit profile. Given that the average life expectancy in patients with vertebral metastasis is 1 year, ${ }^{1}$ surgery is undesirable since the postoperative recovery consumes much of the remainder of life. Therefore, nonoperative and minimally invasive techniques are the most appropriate treatment options for vertebral metastases.

Percutaneous vertebral augmentation is a minimally invasive procedure involving the injection of polymethylmethacrylate (PMMA) into a vertebral body that is either partially collapsed or at high risk for collapse due to osteolysis. Vertebral augmentation
The Jon Block Group, 2210 Jackson

Street, Suite 40I, San Francisco,

CA 94115 , USA

$\mathrm{Tel}+\mathrm{I} 4157757947$

Fax + I 4I59280765

Email jonblock@jonblockgroup.com 
is appealing as an adjunct to radiotherapy or chemotherapy in patients with malignancy for alleviation of intractable pain, despite comprehensive nonoperative management. Several studies have reported dramatic improvements in pain severity associated with osteolytic vertebral metastases following percutaneous vertebral augmentation. ${ }^{2-4}$ However, percutaneous vertebral augmentation is associated with higher risk of complications from PMMA extravasation in cancer patients compared with osteoporotic patients due to loss of cortical integrity. ${ }^{5}$ As such, malignancy is widely considered a relative contraindication for these procedures. Described in this report is the case of a painful osteolytic vertebral metastasis that was successfully treated by percutaneous vertebral augmentation using a novel coil-shaped polyetheretherketone (PEEK-OPTIMA ${ }^{\circledR}$, Victrex PLC, Lancashire, UK) implant designed to minimize the risk of PMMA extravasation.

\section{Case presentation}

A 42-year-old Caucasian female was referred to our institution in June 2011 for evaluation of pain palliation using percutaneous vertebral augmentation. The patient presented with a 4-year history of metastatic lung cancer unresponsive to radiation and chemotherapy, with symptoms inadequately controlled by opiates over the previous 6 months. The patient reported pain severity of 10 on an 11-point visual analogue scale and back disability of $89 \%$ on the Oswestry Disability Index. Magnetic resonance imaging and spiral computed tomography (CT) with twodimensional reconstruction revealed an osteolytic vertebral metastasis with complete involvement of the T10 vertebral body, extending to the cortical vertebral wall anteriorly and posteriorly (Figure 1).

Immediately prior to the procedure, the patient was premedicated with intravenous antibiotics (vancomycin hydrochloride $1 \mathrm{~g}$ and gentamycin $100 \mathrm{mg}$ ). The patient was placed in the prone position on the table of the angiographic suite, and the procedure was carried out with digital hybrid fluoroscopic and CT guidance. The entire procedure was performed under local anesthesia ( $3 \mathrm{~mL}$ of $2 \%$ lidocaine hydrochloride at the skin level and deep to include the periosteum) along with continuous monitoring of vital parameters.

The PEEK implant is part of the Kiva ${ }^{\circledR}$ VCF Treatment System (Benvenue Medical, Inc, Santa Clara, CA) and is offered in a kit containing an access needle, Kirschner guide-wire, dilator with working cannula, delivery system with nitinol coil guide-wire, and the implant bone cement and its manual screw injection system. The Kiva System received CE Mark approval in December 2008.

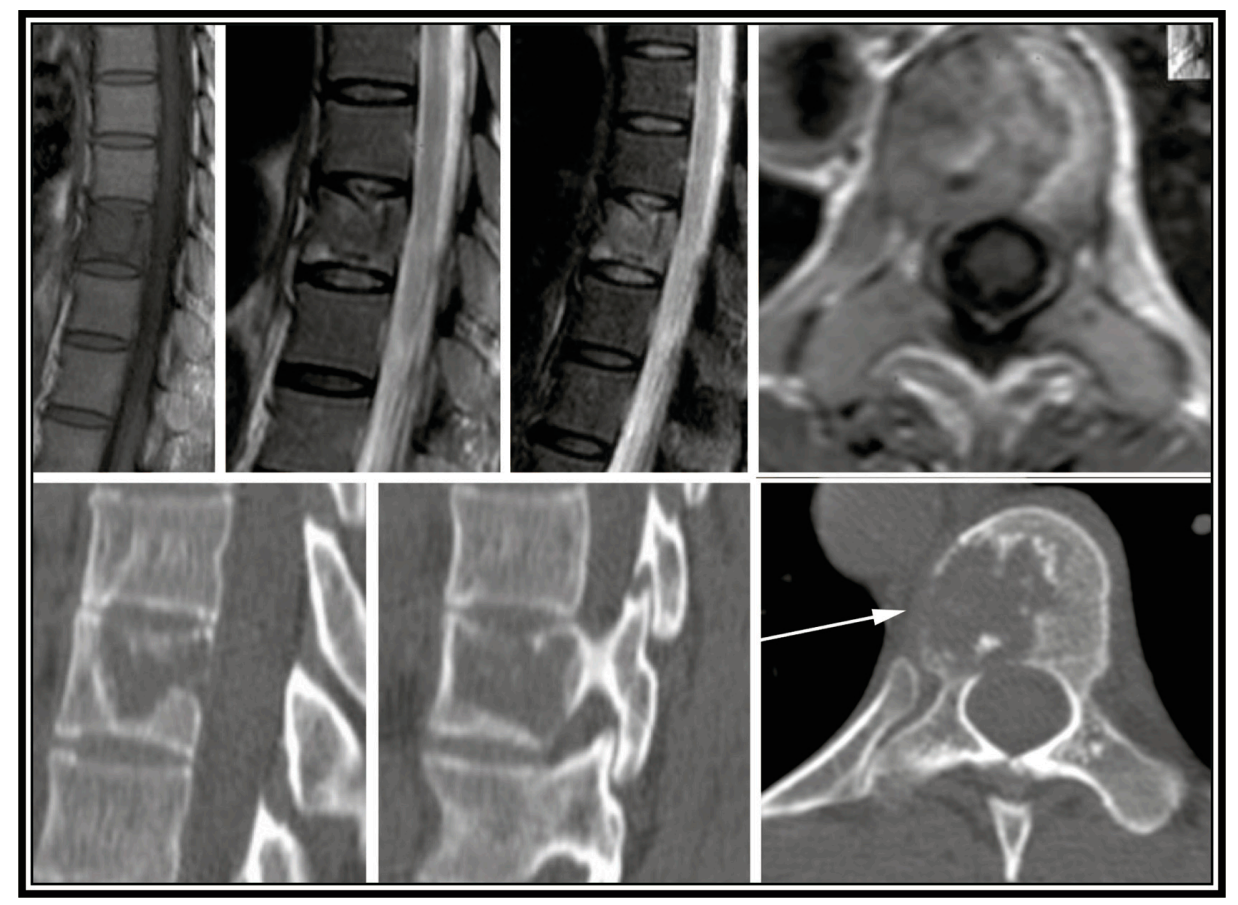

Figure I Preoperative imaging demonstrating osteolytic vertebral metastasis with complete involvement of the TIO vertebral body, extending to the cortical vertebral wall anteriorly and posteriorly.

Notes: T2-weighted short TI inversion recovery magnetic resonance imaging (top row). Computed tomography (bottom row). Arrow shows the boundary of the bulging metastasis through the cortical wall.

Abbreviation: $\mathrm{Tl}$, time to inversion. 
After a percutaneous approach was accomplished with an 11-gauge needle manually inserted through the costotransversal (extra-pedicular) route to reach the midline and close to the upper endplate of the T10 vertebral body (Figure 2A), a Kirschner guide-wire was inserted to allow the placement of a 6-gauge working cannula (Figure 2B). Through the 6-gauge introducer, the delivery system was inserted to allow the deployment of a nitinol coil-shaped guide-wire into the vertebral body (Figure 2C). The Kiva implant was then delivered

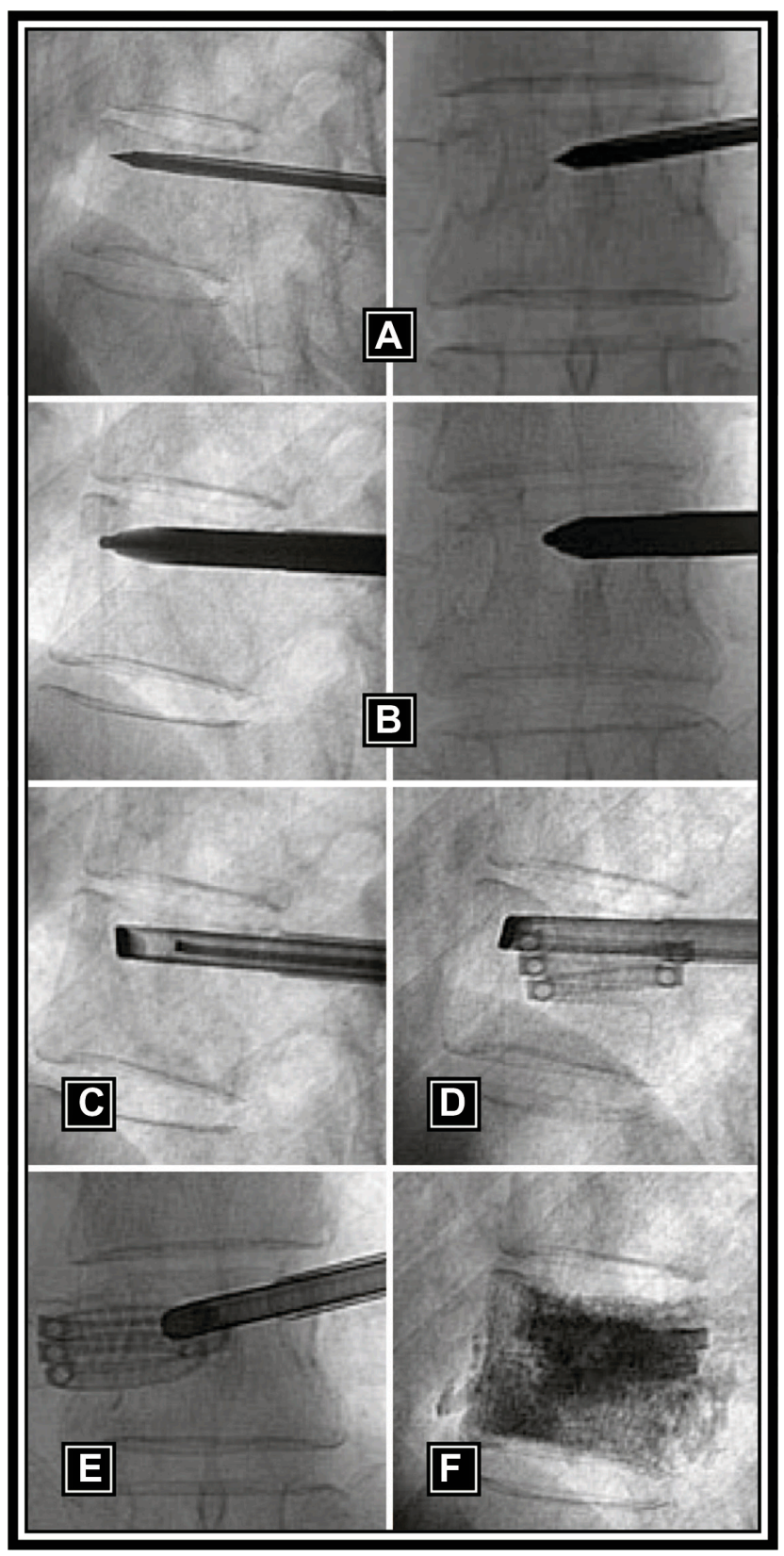

Figure 2 Intraoperative images demonstrating: (A) access with II-gauge needle; (B) introduction of the dilator; (C) placement of working cannula in lateral view with $\mathrm{Kiva}^{\circledR}$ Coil showing; (D) deployed Kiva implant in lateral view; (E) deployed Kiva implant in anteroposterior view; and $(\mathbf{F})$ completed procedure with cement fill. over the nitinol guide-wire (Figure 2D) inside the osteolytic lesion of the vertebra (Figure 2E) to form a nesting, cylindrical column. Up to four loops of the implant may be inserted into the vertebral body for a maximum coil stack of $12 \mathrm{~mm}$, which re-elevates the endplate. After the coil was retracted, a total of $6 \mathrm{~mL}$ of radiopaque bone cement was gradually injected using a manual screw injector through the Kiva implant and its inner holes under fluoroscopic monitoring (Figure 2F). Post-procedural CT scan with multi-planar reformatting demonstrated a satisfactory bone cement distribution within the vertebral body and the complete absence of extravasation either anteriorly or posteriorly (Figure 3). The minimally invasive procedure was successfully concluded without clinical complication. Pain severity decreased from 10 to 0 within 48 hours, and analgesic opiate use was suspended. Back disability improved from $89 \%$ to $2 \%$. The patient was followed at 15 days, 1 month, 6 weeks, and 4 months posttreatment. Complete pain relief was maintained throughout 4 months of follow-up with no further need of analgesia.

\section{Discussion}

The treatment of painful vertebral metastases is a major therapeutic challenge. Radiation therapy is only marginally effective with mediocre pain relief durability. Further, previously radiated vertebral levels are at elevated risk for collapse, with potentially devastating neurologic consequences. This case report shows that percutaneous vertebral augmentation using the novel coil-shaped PEEK Kiva implant is feasible, effective, and may reduce the risk of PMMA extravasation in the treatment of painful osteolytic vertebral metastases with diffuse cortical bone involvement. The results of this report are novel in that the Kiva implant represents a new therapeutic option for the treatment of painful vertebral metastasis where radiation therapy, traditional surgical stabilization, or balloon-based vertebral augmentation procedures may be contraindicated.

Chew et $\mathrm{al}^{3}$ conducted a systematic review on the safety and efficacy of percutaneous vertebral augmentation for spinal metastases and myeloma. Although vertebral augmentation reduced pain severity by $47 \%-87 \%$, serious complications were reported in up to $12 \%$ of patients. The risk of cement extravasation is also notably higher in malignancies due to high vascularization and osseous destruction. ${ }^{5}$ Resulting complications may include intercostal neuralgia, radiculopathy, myelopathy, or spinal infections. ${ }^{6}$ The Kiva System was designed to reduce and stabilize vertebral fractures by deploying a coiled PEEK implant, which is then augmented with cement. PMMA bone cement is injected 


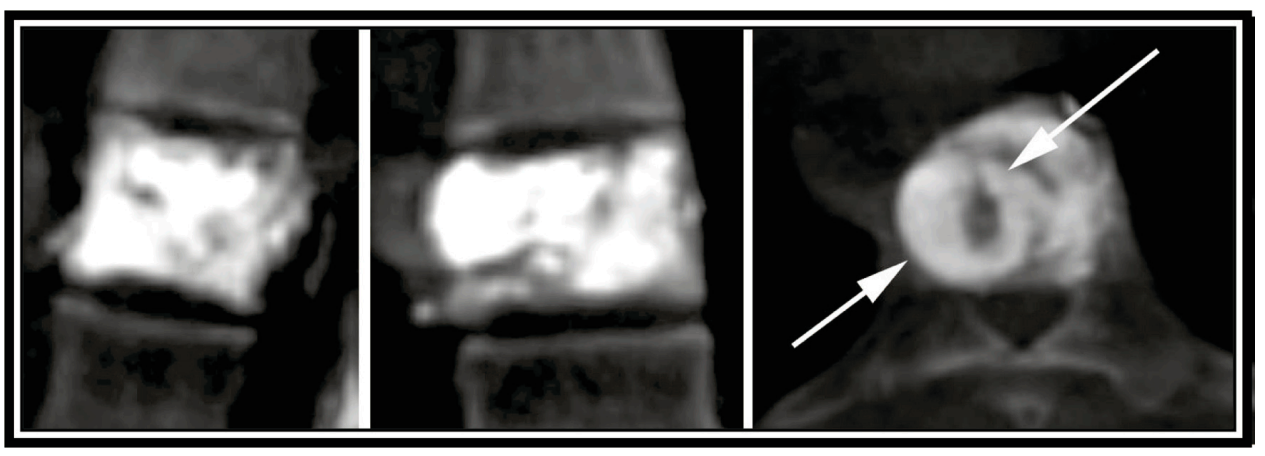

Figure 3 Reformatted postoperative computed tomography scan demonstrating satisfactory bone cement distribution within the TI0 vertebral body and the complete absence of extravasation either anteriorly or posteriorly.

Note: Arrows show coil implant boundaries.

through the lumen of the Kiva implant, which helps to contain and control the distribution of the cement. Once cured, the cement interlocks the implant to the cancellous bone. With traditional kyphoplasty and vertebroplasty procedures, PMMA is injected into cancellous bone, but there is no mechanism for cement containment. Consequently, PMMA cement may leak laterally to the soft tissues, superiorly or inferiorly into the adjacent disc space, or posteriorly, where it may involve the exiting nerve root or the spinal canal. ${ }^{6}$

A recent clinical study was conducted with the Kiva System in 26 patients (42 fractures) for treatment of vertebral compression fractures. ${ }^{7}$ Anterior cement extravasation was identified at $4.8 \%$ of levels with no reported intracanal extravasation or adverse clinical sequelae. These results compare favorably to cement extravasation rates of $7 \%-72 \%$ reported in previous studies. ${ }^{8-12}$

The mechanism of pain amelioration with percutaneous vertebral augmentation is currently unknown, although two main hypotheses prevail. Polymethyl methacrylate cement stabilizes vertebral microfractures, which eliminates painful vertebral body and periosteal micromovements. ${ }^{13}$ In addition, the thermal polymerization of PMMA following injection ablates pain receptors in trabecular bone, in vertebral periosteum, and in vascular structures. ${ }^{14}$ The combination of these two proposed factors leads to immediate postoperative anterior column stability and pain relief. ${ }^{4}$

\section{Conclusion}

The Kiva System represents a novel and effective minimally invasive treatment option for patients suffering from severe pain due to osteolytic vertebral metastasis. The novel design of the Kiva implant may reduce the risk for PMMA extravasation versus traditional vertebral augmentation procedures. Prospective studies are needed to validate the safety and effectiveness of this device in patients with vertebral metastasis.

\section{Consent}

Written informed consent was obtained from the patient for publication of this case report and accompanying images.

\section{Acknowledgments and funding}

No funds were received to support the clinical management of patients in this study. Manuscript development was supported, in part, by Benvenue Medical, Inc, (Santa Clara, CA). Benvenue Medical, Inc, had no involvement in the study design, collection, analysis, and interpretation of data, writing the manuscript, or the decision to submit the manuscript for publication.

\section{Disclosure}

The authors declare that they have no competing interests in this work.

\section{References}

1. Aebi M. Spinal metastasis in the elderly. Eur Spine J. 2003;12 Suppl 2: S202-S213.

2. Tancioni F, Lorenzetti MA, Navarria P, et al. Percutaneous vertebral augmentation in metastatic disease: state of the art. J Support Oncol. 2011;9(1):4-10.

3. Chew C, Craig L, Edwards R, Moss J, O'Dwyer PJ. Safety and efficacy of percutaneous vertebroplasty in malignancy: a systematic review. Clin Radiol. 2011;66(1):63-72.

4. Fourney DR, Schomer DF, Nader R, et al. Percutaneous vertebroplasty and kyphoplasty for painful vertebral body fractures in cancer patients. J Neurosurg. 2003;98(Suppl 1):21-30.

5. Mousavi P, Roth S, Finkelstein J, Cheung G, Whyne C. Volumetric quantification of cement leakage following percutaneous vertebroplasty in metastatic and osteoporotic vertebrae. J Neurosurg. 2003;99(Suppl 1): 56-59.

6. Mirovsky Y, Anekstein Y, Shalmon E, Blankstein A, Peer A. Intradiscal cement leak following percutaneous vertebroplasty. Spine (Phila Pa 1976). 2006;31(10):1120-1124. 
7. Korovessis P, Repantis T, Miller LE, Block JE. Initial clinical experience with a novel vertebral augmentation system for treatment of symptomatic vertebral compression fractures: a case series of 26 consecutive patients. BMC Musculoskelet Disord. 2011;12(1):206.

8. Bouza C, Lopez T, Magro A, Navalpotro L, Amate JM. Efficacy and safety of balloon kyphoplasty in the treatment of vertebral compression fractures: a systematic review. Eur Spine J. 2006;15(7):1050-1067.

9. Eck JC, Nachtigall D, Humphreys SC, Hodges SD. Comparison of vertebroplasty and balloon kyphoplasty for treatment of vertebral compression fractures: a meta-analysis of the literature. Spine J. 2008;8(3):488-497.

10. Taylor RS, Fritzell P, Taylor RJ. Balloon kyphoplasty in the management of vertebral compression fractures: an updated systematic review and meta-analysis. Eur Spine J. 2007;16(8):1085-1100.
11. Wardlaw D, Cummings SR, Van Meirhaeghe J, et al. Efficacy and safety of balloon kyphoplasty compared with non-surgical care for vertebral compression fracture (FREE): a randomised controlled trial. Lancet. 2009;373(9668):1016-1024.

12. Klazen CA, Lohle PN, de Vries J, et al. Vertebroplasty versus conservative treatment in acute osteoporotic vertebral compression fractures (Vertos II): an open-label randomised trial. Lancet. 2010;376(9746):1085-1092.

13. Weill A, Chiras J, Simon JM, Rose M, Sola-Martinez T, Enkaoua E. Spinal metastases: indications for and results of percutaneous injection of acrylic surgical cement. Radiology. 1996;199(1):241-247.

14. Levine SA, Perin LA, Hayes D, Hayes WS. An evidence-based evaluation of percutaneous vertebroplasty. Manag Care. 2000;9(3):56-60, 63.

\section{Publish your work in this journal}

The International Medical Case Reports Journal is an international, peer-reviewed open-access journal publishing original case reports from all medical specialties. Previously unpublished medical posters are also accepted relating to any area of clinical or preclinical science. Submissions should not normally exceed 2,000 words or
4 published pages including figures, diagrams and references. The manuscript management system is completely online and includes a very quick and fair peer-review system, which is all easy to use. Visit http://www.dovepress.com/testimonials.php to read real quotes from published authors.

Submit your manuscript here: http://www.dovepress.com/international-medical-case-reports-journal-journal 